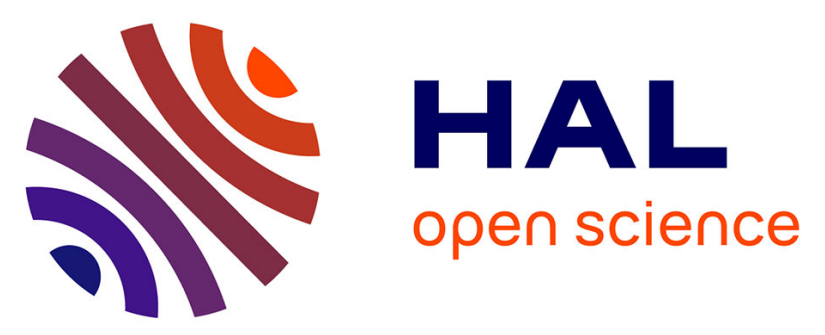

\title{
New insight in the preparation of alumina supported hydrotreatment oxidic precursors: A molecular approach.
}

\author{
Pascal Blanchard, Carole Lamonier, Anne Griboval, Edmond Payen
}

\section{To cite this version:}

Pascal Blanchard, Carole Lamonier, Anne Griboval, Edmond Payen. New insight in the preparation of alumina supported hydrotreatment oxidic precursors: A molecular approach.. Applied Catalysis A : General, 2007, 322, pp.33-45. 10.1016/japcata.2007.01.018 . hal-00342710

\author{
HAL Id: hal-00342710 \\ https://hal.science/hal-00342710
}

Submitted on 28 Nov 2008

HAL is a multi-disciplinary open access archive for the deposit and dissemination of scientific research documents, whether they are published or not. The documents may come from teaching and research institutions in France or abroad, or from public or private research centers.
L'archive ouverte pluridisciplinaire HAL, est destinée au dépôt et à la diffusion de documents scientifiques de niveau recherche, publiés ou non, émanant des établissements d'enseignement et de recherche français ou étrangers, des laboratoires publics ou privés. 


\title{
NEW INSIGHT IN THE PREPARATION OF ALUMINA SUPPORTED HYDROTREATMENT OXIDIC PRECURSORS: A MOLECULAR APPROACH
}

\author{
P. Blanchard, C. Lamonier, A. Griboval, E. Payen \\ Unité de Catalyse et Chimie du Solide, UCCS C.N.R.S Nº 8181, Université des Sciences \\ et Technologies de Lille, Bâtiment C3, 59655 Villeneuve d'Ascq, France.
}

Keywords : Hydrotreatment, Catalysis, Heteropolyanions, Complexing agent, Thiophene

\begin{abstract}
The science on the preparation of the hydrodesulfurization oxidic precursors is coming of age, but the chemistry governing their preparation is not yet clearly understood. In this paper, the chemistry of alumina supported oxomolybdate preparation is revisited taking into account the dissolution/precipitation concept recently developed. Classical preparations with the ammonium heptamolybdate and Co nitrate salts will firstly be discussed. Then the use of new starting materials for the preparation of the impregnating solutions will be considered, showing that at high Mo loading the dispersion is strongly dependant on the nature of the starting salts. The use of phosphomolybdate cobalt salts will also be considered. Lastly we will discuss the improvement of the Co promoting effect using molybdocobaltate heteropolyanions as starting materials and complexing agents. This study shows that the maturation step is the determining step for the improvement of preparation of these alumina based oxidic precursor.
\end{abstract}

\section{Introduction}

Heterogeneous Catalysis plays an important role in the development of environmentally sustainable technologies which span across many important industries such as oil refining, petrochemicals, fine chemicals, power generation and natural gas conversion. More and more stringent regulations on the pollutant emissions impose to improve these processes. In this context the improvement in the preparation of Hydrodesulfurization (HDS) catalysts has been driven by the need to produce clean fuels, based on the pressing requirement for environmental protection. The most industrially used catalyst is the $\mathrm{CoMo} / \mathrm{Al}_{2} \mathrm{O}_{3}$, the active phase of which consists of well dispersed $\mathrm{MoS}_{2}$ nanocrystallites 
decorated with Co or Ni promoter atoms according to the Topsoe's model [1]. These phases are obtained by sulfidation of an oxidic precursor that is generally prepared by incipient wetness impregnation of an alumina support with ammonium heptamolybdate (AHM) and cobalt or nickel nitrate solutions. In this method which is the most industrially used one, the volume of solution corresponds to the pore volume of the support, whereas in the equilibrium adsorption method the impregnation proceeds with an excess of solution, that is after eliminated by filtration. These solids are then dried and calcined in order to mainly remove the nitrate and ammonium counterions present in these conventional preparations. Improvement of the catalytic performances implied a more complete understanding of the structure and genesis of the oxidic precursor, which permitted the development of new preparation methods.

The various steps of the preparation of these $\mathrm{CoMo} / \mathrm{Al}_{2} \mathrm{O}_{3}$ oxidic precursors will be revisited in this paper. The Dissolution/Precipitation concept that has been recently developed in the litteratur $[2,3]$ will firstly be presented. It will allow us to discuss the exact nature of the alumina supported oxomolybdate phase of conventional preparations. We will then discuss the formulation of new impregnating solutions and their preparation with new heteropolymolybdates as starting materials or with complexing agents, which permit to propose a new molecular design of the HDS oxidic precursor with improvement of the catalytic properties.

\section{Experimental}

In this section we only present the main techniques used for the characterizations and the preparation. Experimental details have been described previously in the cited references.

\section{II.1. Characterization techniques}

\section{- XAS STUDY}

Mo and Co K-edge EXAFS (Extended X-ray Absorption Fine Structure) measurements were carried out in the Laboratoire pour l'Utilisation du Rayonnement Electromagnétique (Orsay), at the EXAFS D42 and D44 beamlines, otherwise stated. The synchrotron radiation from the DCI storage ring, running at $1.85 \mathrm{GeV}$ with an average current of $250 \mathrm{~mA}$ was used.

\section{- Raman spectroscopy}

The Raman spectra of the samples, maintained at room temperature, were recorded using a Raman microprobe (Infinity from Jobin-Yvon), equipped with a photodiode array detector. The exciting laser source was the $532 \mathrm{~nm}$ line of a Nd-YAG laser, the power at the 
sample was less than $1 \mathrm{~mW}$. The wavenumber accuracy was $2 \mathrm{~cm}^{-1}$. In situ characterization of the oxidic precursor was obtained with a cell that was directly fitted on the microscope stage.

- NMR measurements

The ${ }^{31} \mathrm{P}$ NMR measurements of the solutions were carried out on a bruker AC300 spectrometer. Chemical shifts are negative towards higher field and are referenced to external $85 \% \mathrm{H}_{3} \mathrm{PO}_{4}$ as a standard. The solvent used is $\mathrm{H}_{2} \mathrm{O}$ and all the solutions were prepared at 1.5 mol Mo per litre, i.e. the concentration of the impregnating solutions. The pulse length and the relaxation time were respectively equal to $1.8 \mu \mathrm{s}$ and $20 \mathrm{~s}$.

\section{II.2. Preparation of the oxidic precursors}

HDS oxidic precursors were prepared by incipient wetness impregnation of $\gamma$ alumina extrudates with aqueous impregnating solutions, the formulation of which is the main purpose of the paper and will be discussed hereafter. Otherwise stated, the specific surface area (SSA) and the pore volume of the alumina used are respectively $250 \mathrm{~m}^{2} / \mathrm{g}$ and $0.6 \mathrm{~cm}^{3} / \mathrm{g}$. After impregnation, the solids were let two hours at $20^{\circ} \mathrm{C}$ under $\mathrm{H}_{2} \mathrm{O}$ pressure vapour for maturation, in order to let the species diffuse into the alumina extrudates. Then the solids were dried under air at $100^{\circ} \mathrm{C}$ and calcined at $500^{\circ} \mathrm{C}$ for $4 \mathrm{~h}$ under oxygen otherwise stated. These oxidic precursors have been designated as $\mathrm{xCoMo}_{\mathrm{y}}, \mathrm{x}$ being the $\mathrm{Co} / \mathrm{Mo}$ atomic ratio and $\mathrm{y}$ the molybdenum loading expressed as a weight percent of $\mathrm{MoO}_{3}$. The oxidic precursors prepared with modified impregnating solution are designated as the aforementioned ones in which the modifying agent is stated, i.e. $\mathrm{P}$ or En (Ethylenediamine), after the name (xCoMoyP or xCoMoyEn). Whatever the solids, the starting materials used for the preparation of the impregnating solutions is designated between brackets. Otherwise stated, the Co-based precursor is always cobalt nitrate and the $\mathrm{P} / \mathrm{Mo}$ atomic ratio used for the preparation of conventional phosphorus based catalysts (prepared with $\mathrm{H}_{3} \mathrm{PO}_{4}$ ) is always 2/5.

The Mo and Co loadings were determined by X-ray fluorescence by the "Service Central d'Analyses du CNRS" (Vernaison-France).

Table 1 reports the denomination of the catalysts, the starting materials used for the preparation of the impregnating solutions, the Mo weight loading expressed as a weight percent of $\mathrm{MoO}_{3}$, the $\mathrm{Co} / \mathrm{Mo}$ atomic ratio and the $\mathrm{P} / \mathrm{Mo}$ atomic ratio for the phosphorus based catalysts or the En/Co molar ratio for the catalysts prepared with this complexing agent.

\section{II.3. Catalytic activities}

Whatever their preparation method, the catalytic performances of these solids were evaluated after calcination and transfer in air otherwise stated. The solids were firstly sulfided 
at $673 \mathrm{~K}$ for 2 hours under a flow $\left(70 \mathrm{~mL} \cdot \mathrm{min}^{-1}\right)$ of $\mathrm{H}_{2} \mathrm{~S} / \mathrm{H}_{2}(10 / 90)$ mixture in the catalytic reactor. Secondly the temperature was cooled down to $573 \mathrm{~K}$ for the evaluation of the thiophene HDS conversion. The catalytic activities were measured at atmospheric pressure in a flow-bed reactor packed with $200 \mathrm{mg}$ of catalyst. After purification by vacuum distillation, thiophene was introduced in the reactor at constant pressure (50 torrs) in a flow of purified hydrogen $\left(10 \mathrm{~mL} \cdot \mathrm{min}^{-1}\right)$. The reaction products (butane and butene) were analysed by gas chromatography.

\section{Conventional preparations}

\section{III.1. Mo and $\mathrm{CoMo} / \mathrm{Al}_{2} \mathrm{O}_{3}$}

\section{III.1.a. Unpromoted catalysts}

Efforts of rationalization have been performed this last decade to explain the formation of the alumina supported oxomolybdate phases. It has been claimed that upon impregnation, a direct adsorption of the entities present in the impregnating solution occurs on the surface sites of the alumina [4]. The detailed description of the structure and genesis of these alumina supported oxomolybdenum catalysts in their oxide state owes much to results obtained using Raman spectroscopy. Upon increasing the Mo loading, three types of species are identified [5] i.e.:

- isolated tetrahedral entities, characterized by a main line at $920-930 \mathrm{~cm}^{-1}$, at low Mo loading (typically below $0.6 \mathrm{Mo}$ per $\mathrm{nm}^{2}$ ).

- a polymolybdate phase, characterized by the main Raman line at $952 \mathrm{~cm}^{-1}$, up to a Mo coverage of 3.5 Mo at per $\mathrm{nm}^{2}$.

- microcrystallittes $\mathrm{MoO}_{3}$, characterized mainly by the lines at 820 and $996 \mathrm{~cm}^{-1}$, are then observed with the aforementioned polymolybdate phase. The appearance of this well defined oxide corresponds to the limit of good dispersion as determined by XPS [6].

Various schemes of adsorption, represented in figure 1, were then proposed. At low Mo loading (typically below $0.6 \mathrm{Mo}$ per $\mathrm{nm}^{2}$ i.e. $3 \mathrm{wt} \% \mathrm{MoO}_{3}$ for a classical HDS alumina support like the one used in this work), the adsorption of the monomolybdate through anionic exchange with the basic surface hydroxyl groups of the alumina has been proposed. At higher loading, various modes of adsorption of the heptamolybdate anions on the same sites were also considered [7]. Hence extensive modelling studies of molybdate adsorption isotherms were also performed by the Lycourghiotis's groups [8]. But the exact nature of the alumina surface site in presence of the impregnating solution and the exact nature of the polymolybdate phase were never clearly established. 
In all these studies the oxide support was always considered as inert and never as a real reagent. But recent studies have shown that an extensive support dissolution may occur even at $\mathrm{pH}$ values between 7 and 8 , a range in which the alumina is generally considered as being non soluble [2,3]. Molybdenum is a versatile element which may create various heteropolystructures with many elements as shown in figure 2. In presence of $\mathrm{Al}(\mathrm{III})$ the isopolymolybdate can yield a heteropolymolybdate anion. Figure $2 \mathrm{a}$ shows the structure of this Anderson type heteropolyanion (HPA) with structural formula $\left[\mathrm{Al}(\mathrm{OH})_{6} \mathrm{Mo}_{6} \mathrm{O}_{18}\right]^{3-}$ $\left(\mathrm{AlMo}_{6}\right)$. This is a flat structure that consists of a crown of six $\mathrm{MoO}_{6}$ octahedra surrounding a central $\mathrm{Al}$ atom. Non acidic protons are located on the $\mathrm{Al}$ Mo bridging oxygen atoms.

Figure 3 shows the Raman spectra after the different stages of preparation of an oxidic precursor with a Mo loading lower than the aforementioned limit of good dispersion. It clearly shows that after maturation (Fig. 3c) the AHM features (Fig 3a) are no longer observed whereas the spectrum is similar to the $\mathrm{AlMo}_{6}$ aqueous solution (Fig. 3b) which suggests the presence of $\mathrm{AlMo}_{6}$ entities that are isolated as in the solution. Various other physical techniques $\left({ }^{27} \mathrm{Al}\right.$ static or MAS-NMR, XAS-EXAFS and XANES) have also been used to show its formation [9]. Whatever the method of impregnation, i.e. the equilibrium or the incipient wetness one, the ${ }^{27} \mathrm{Al}$ NMR spectrum of the wet solid exhibits a broad line at $15 \mathrm{ppm}$ characteristic of these $\mathrm{AlMo}_{6}$ entities. Its presence in solution in the pores of the support was also confirmed by liquid ${ }^{95}$ Mo NMR spectroscopy by the characteristic line of AlMo6 at -20 ppm. Carrier \& al. also showed the quantitative formation of this $\mathrm{AlMo}_{6} \mathrm{HPA}$ through characterizing the solution during an equilibrium adsorption preparation. [9]. This allows us to consider that, after the maturation, these species are present in solution in the pores of the alumina support as well dispersed entities. At low Mo loading this $\mathrm{AlMo}_{6}$ entity is not observed. The Raman spectrum only exhibits the line at 898 and $920 \mathrm{~cm}^{-1}$ respectively characteristic of the $\mathrm{MoO}_{4}{ }^{2-}$ species in solution in the pores and adsorbed on the alumina support [5].

It has also been shown that no modification is observed after drying (Fig 3d). This suggests that the $\mathrm{AlMo}_{6}$ entities remain well dispersed on the alumina surface. But upon calcination, these well dispersed surface $\mathrm{AlMo}_{6}$ entities are transformed. Indeed, the XANES spectrum of the calcined solids exhibits an intense pre-edge characteristic of the tetrahedral environment [10]. Moreover, the Raman spectrum (Fig 3f) exhibits a main line at $1000 \mathrm{~cm}^{-1}$ that has been assigned to the stretching mode of the molybdenyl group $\left(\mathrm{MoO}_{\mathrm{t}}\right)$ in distorded tetrahedral entities [11,12]. This suggests that upon calcination the $\mathrm{AlMo}_{6}$ entities are decomposed and that the oxomolybdate surface phase consists of distorted tetrahedral entities 
with single molybdenyl groups that are linked to the support. However upon transfer in the wet air, these $\mathrm{AlMo}_{6}$ entities are recovered as shown by the Raman spectrum (Fig 3e) that exhibits the features of the well dispersed $\mathrm{AlMo}_{6}$ entities.

At Mo loadings higher than the aforementioned limit of good dispersion (3.5 Mo at per $\mathrm{nm}^{2}$ ), the Raman spectrum (Fig 4b) exhibits the features of the ammonium 6-molybdoaluminate salt (Fig 4a). This shows that a precipitation of this salt occurs during the maturation, which leads to the formation of $\mathrm{MoO}_{3}$ microcrystallites upon calcination (Fig 4c). Indeed the Raman spectrum of the calcined solid after transfer in air exhibits the lines at 820 and $996 \mathrm{~cm}^{-1}$ that are characteristic of this oxide.

\section{III.1.b. Co promoted catalysts}

Only catalysts with Mo loadings corresponding to the limit of good dispersion will be considered hereafter. The formation of the well dispersed $\mathrm{AlMo}_{6}$ entities is evidenced by Raman spectroscopy on these cobalt-promoted oxidic precursors after maturation (Fig 5a) [13]. But thanks to the spatial resolution capabilities of the Raman microprobe that enables us to analyse selected particles, heterogeneities are evidenced at high Co loading. Indeed, other well defined Raman features are observed as shown in fig $5 \mathrm{~b}$ and $5 \mathrm{c}$. The former one is characteristic of the $\mathrm{AlMo}_{6}$ ammonium salt precipitate whereas the exact nature of the latter is not yet clearly established. It can be assigned to the formation of a mixed CoMo oxyhydroxide phase. Upon calcination, this heterogeneity is confirmed. Indeed, the Raman spectrum exhibits the lines characteristic of the aforementioned isolated tetrahedral entities (main lines at 1000 and $840 \mathrm{~cm}^{-1}$, spectrum not reported here) [3], and after transfer the well dispersed $\mathrm{AlMo}_{6}$ entities are restored (Fig 6a). But the Raman spectra of these calcined solids also exhibit after transfer in wet air the features of well defined crystalline phases, i.e the (a) $\mathrm{CoMoO}_{4}$ phase (Fig 6b) [14] with the main lines at 940 and $818 \mathrm{~cm}^{-1}$ and the $\mathrm{MoO}_{3}$ oxide

(Fig 6c) with the main lines at 995 and $819 \mathrm{~cm}^{-1}$. These well defined phases should originate from the aforementioned CoMo oxyhydroxide phase and ammonium 6-molybdoaluminate precipitate evidenced before the calcination.

\section{III.2. Conventional phosphorus based catalyst preparation}

\section{III.2.a. Ammonium heptamolybdate based impregnating solutions}

It is now well admitted that the addition of Phosphorus in conventional impregnating solutions (AHM based solutions) has a beneficial effect on the catalytic properties. However, the exact origin of this improvement was not clearly established. Although it has been 
proposed that phosphorus could have a catalytic role [15], some authors have proposed that the main role of phosphorus is to improve the dispersion of the active metals [16]. Morales et al. have suggested that $\mathrm{P}$ occupies the tetrahedral sites of the alumina, impeding the formation of a $\mathrm{Ni}(\mathrm{Co}) \mathrm{Al}_{2} \mathrm{O}_{4}$ type phase and thus increasing the amount of octahedrally coordinated $\mathrm{Ni}(\mathrm{Co})^{2+}$ ions available for the formation of the $\mathrm{Ni}(\mathrm{Co}) \mathrm{MoS}$ phase [17]. Other studies have proposed that the presence of phosphorus leads to the formation of P-Mo heteropolycompounds in the oxide form of the catalysts $[18,19]$.

The formation of the diphosphopentamolybdate HPA, the structure of which been given in Fig 2f, has been clearly evidenced upon addition of phosphoric acid in the abovementioned CoMo impregnating solutions [20-22] as shown in Figure 7a,b. These spectra are characteristic of this HPA by reference to literature data[23]. No other oxomolybdate entities are evidenced at a $\mathrm{P} / \mathrm{Mo}$ atomic ratio of $2 / 5$, a ratio that corresponds to the optimum $\mathrm{P}$ loading [16]. After impregnation of the alumina support with such a solution and drying, the main lines characteristic of this HPA are still observed (Fig 7c) with an intense line at $880 \mathrm{~cm}^{-1}$ which has not yet been assigned. This shows that a partial decomposition of the $\mathrm{P}_{2} \mathrm{Mo}_{5} \mathrm{O}_{23}{ }^{6-}$ anion occurs during the maturation as suggested by others authors [7, 24, 25], even if others considered that this entity is stable in the pores of alumina [20]. These contradictions could be assigned to the different experimental conditions under which these studies were carried out. Indeed, such a partial preservation is possible as the $\mathrm{pH}$ at the zero point of charge of the solid is inside the $\mathrm{pH}$ range of stability of this HPA (i.e. 4-6).

Upon calcination these entities are transformed into the aforementioned tetrahedral adsorbed entities and upon transfer in the wet atmosphere the $\mathrm{AlMo}_{6}$ entities are restored as shown by Raman spectra in Fig 7d and 7e. Consequently, whatever the metal loadings, the formation of the diphosphopentamolybdate stabilizes the impregnating solution and inhibits the formation of the CoMo oxyhydroxide phase and the precipitation of the ammonium 6-molybdoaluminate. This explains the absence of cobalt molybdate and molybdenum oxide microcrystallites on the calcined catalysts that was evidenced on solids prepared with the conventional starting materials. Moreover, Bergwerff et al. have shown, by time resolved in situ Raman microscopy, that the formation of such phosphomolybdenum complexes facilitates the transport of molybdenum entities inside the alumina extrudates by decreasing the interaction between Mo and alumina. The formation of $\mathrm{AlMo}_{6}$ entities in large amount near the outer surface of the support bodies, that could be obtained after impregnation with an acidic AHM solution on $\mathrm{Al}_{2} \mathrm{O}_{3}$, is thus inhibited [26]. 


\section{III.2.b. $\mathrm{MoO}_{3}$ based impregnating solutions}

Molybdo-phosphate based impregnating solutions can also be obtained by direct dissolution of molybdenum oxide with a phosphoric acid solution [27]. Figure 8a and 8c show the Raman spectra of such solutions that are characteristic of the Dawson HPA $\left(\mathrm{P}_{2} \mathrm{Mo}_{18} \mathrm{O}_{62}{ }^{6-}\right)$ [28], the structure of which being given in figure $2 \mathrm{~d}$. The formation of this HPA was also evidenced by P NMR spectroscopy by a line at $-2.45 \mathrm{ppm}$ as shown in figure 9 [28]. Its formation is observed for a $\mathrm{P} / \mathrm{Mo}$ atomic ratio higher or equal to $1 / 9$. This figure shows that, at an atomic ratio $\mathrm{P} / \mathrm{Mo}=2 / 5$ corresponding to the one used for the impregnating solution, the dawson entity is the main Mo based one present in solution. But the presence of free phosphates in large amount and of the $\mathrm{H}_{6} \mathrm{PMo}_{9} \mathrm{O}_{34}{ }^{3-}$ anion in very low amount is also evidenced by respectively the intense line at 0.5 and the line at $-0.9 \mathrm{ppm}$ [29]. Raman spectroscopy showsthat the Dawson structure (main Raman lines at 974 and $713 \mathrm{~cm}^{-1}$ ) is maintained upon introduction of cobalt nitrate in this MoP based solution as shown in figure $8 \mathrm{c}$ whereas a decomposition is observed upon addition of the cobalt as a carbonate salt. Indeed the Raman spectrum (Fig 8b) exhibits the features of the $\mathrm{P}_{2} \mathrm{Mo}_{5} \mathrm{O}_{23}{ }^{6-} \mathrm{HPA}$ as in the classical aforementioned CoMoP impregnating solution. This decomposition is assigned to the increase of $\mathrm{pH}$ that occurs upon addition of the cobalt carbonate [22]. However, upon impregnation on alumina with the cobalt nitrate based solution, the HPA structure is not maintained as shown in figures $8 \mathrm{~d}$ and $8 \mathrm{e}$. Indeed these Raman spectra exhibit the features of the $\mathrm{PMo}_{9} \mathrm{O}_{34}{ }^{9-}$ (Raman line at $974 \mathrm{~cm}^{-1}$ without the line at $713 \mathrm{~cm}^{-1}$ ) [22] and of the well dispersed AlMo6 entities. This decomposition is assigned to the buffer effect of alumina, the $\mathrm{pH}$ of the solution in the pores being higher than the $\mathrm{pH}$ domain of stability of the Dawson entity. If no calcination is required with the Co carbonate based impregnating solution, as there is no nitrate or ammonium counterions, it is necessary to eliminate the nitrate anions in the Co nitrate based one. Calcination followed by the transfer in wet atmosphere induces the decomposition of the remaining $\mathrm{PMo}_{9} \mathrm{O}_{34}{ }^{9-} \mathrm{HPA}$ structure as shown in figure $8 \mathrm{f}$. The features of $\mathrm{CoMoO}_{4}$ and $\mathrm{MoO}_{3}$ microcrystallites are not observed on the Raman spectra that only exhibit those of the well dispersed $\mathrm{AlMo}_{6}$ phase. This shows that a better dispersion is also obtained at high metal loadings by comparison with solids prepared with the conventional starting materials. Thus, even if after calcination the formation of the same surface species as on conventional prepared oxidic precursor (i.e. with AHM as starting material) is observed, this method of preparation allows us to stabilize the impregnating solution by inhibiting any of the aforementioned precipitates (CoMo oxyhydroxide phase or ammonium 6-molybdoaluminate precipitate). 


\section{III.3. Thiophene conversion}

Table 2 shows the activity in thiophene HDS of conventional CoMo and CoMoP HDS catalysts. At low Co loading, the phosphorus based solids have the same activity than the classical CoMo one (lines 1, 3 and 5). At this low Co loading $(\mathrm{Co} / \mathrm{Mo}=0.125)$, the nature of the surface oxomolybdate is quite similar whatever the impregnating solution used. This shows that, at low metal loading, the presence of phosphorus is not required since it does not play any catalytic role in HDS of thiophene. But whatever the method of its introduction, the presence of $\mathrm{P}$ at high Co loading induces an improvement of the thiophene conversion, which is assigned to a better dispersion of the active metals (lines 2, 4 and 6). Indeed the formation of $\mathrm{CoMoO}_{4}$ and $\mathrm{MoO}_{3}$ microcrystallites was not observed for these CoMoP based catalysts whereas they were evidenced on the CoMo ones. These oxides microcrystallites are difficult to sulfide and yield bulk $\mathrm{Co}_{9} \mathrm{~S}_{8}$ which cannot promote the $\mathrm{MoS}_{2}$ slabs. Finally, whatever the method of preparation of the Phosphorus-based impregnating solutions, the catalytic performances are similar (lines 4 and 6), which confirms the similarity of the surface oxomolybdate phase after calcination.

\section{III.4. Conclusion}

These results clearly show that upon impregnation with AHM solutions, $\mathrm{AlMo}_{6}$ entities are formed inside the alumina pores during the maturation. However at high loadings, a precipitation of its ammonium salt occurs that gives $\mathrm{MoO}_{3}$ crystallites upon calcination. Thus the limit of good dispersion corresponds to the maximum of solubility of the $\mathrm{AlMo}_{6}$ ammonium salt in the pore of the alumina support. Below this limit, the well dispersed $\mathrm{AlMo}_{6}$ entities decomposes upon calcination, but they are restored upon transfer in air. It may thus be considered that the oxidic precursor consists of well dispersed $\mathrm{AlMo}_{6}$ entities in the thin film of water covering the alumina surface and interacting electrostatically with this surface as reported by Carrier [2]. Indeed, the alumina is positively charged thanks to the $\mathrm{pH}$ of the Mo solution in the pore. This well dispersed oxomolybdate phase is also observed on the CoMo oxidic precursor after maturation as well as after calcination and transfer in wet atmosphere. However, upon increasing the Mo and/or the Co loading, a CoMo oxyhydroxide phase and the ammonium 6-molybdoaluminate precipitate are evidenced after the maturation, which yield $\mathrm{MoO}_{3}$ and/or $\mathrm{CoMoO}_{4}$ microcrystallites upon calcination as shown by Raman microscopy. Thus, the formation of these precipitates is detrimental to the metal dispersion as well as to the catalytic performances. These microcrystallites remain intact upon transfer in a 
wet atmosphere whereas the well dispersed surface $\mathrm{AlMo}_{6}$ entities are restored by hydration of the surface tetrahedral oxomolybdate entities obtained upon calcination. Thus it is always the same well dispersed surface oxomolybdate phase that is activated to give the active sulfided phase, the calcination appearing as a levelling step of the different preparation methods. Nevertheless, an improvement of dispersion is obtained at high metal loadings upon introduction of $\mathrm{P}$ in a conventional CoMo impregnating solution, inducing the formation of a diphosphopentamolybdenum heteropolyanion, the solubity of its ammonium salt being higher than the $\mathrm{AlMo}_{6}$ and CoMo oxyhydroxide one. This allows us to avoid any precipitation. Similar effect can be obtained with the $\mathrm{MoO}_{3}$ based impregnating solutions because another very soluble HPA is deposited, moreover without ammonium counterions in the solution. A better dispersion at high metal loadings as compared to conventional preparations is obtained.

\section{Keggin based CoMoP impregnating solutions}

Fortunately molybdenum can create many heteropolystructures with various elements such as phosphorus, silicium, cobalt or nickel atoms [30]. We therefore proposed the use of Keggin type HPA as starting materials, the structure of which being shown in figure $2 \mathrm{~b}$. The most known is the phosphomolybdic acid, the cobalt salt of which can be prepared by ionic exchange [21] $\left(\mathrm{Co}_{3 / 2} \mathrm{PMo}_{12} \mathrm{O}_{40}\right)$. An impregnating solution containing only the element to be deposited $\left(\mathrm{Co}^{2+}\right.$ and the HPA) can thus be obtained. The Raman spectrum of this solution exhibits, by reference to the literature [31-33], the features of the Keggin structure (Fig 10a: main Raman lines at 990, 603 and $251 \mathrm{~cm}^{-1}$ ). This shows that the Keggin structure is maintained upon this exchange but its decomposition is observed upon deposition on alumina as evidenced on figure $10 \mathrm{~b}$, the Raman spectrum being characteristic of the well dispersed $\mathrm{AlMo}_{6}$ entities. This decomposition is induced by the buffer effect of the alumina. After calcination and transfer in the wet atmosphere, the Raman features of the $\mathrm{AlMo}_{6}$ entities are recovered and the Raman spectrum does not exhibit the features of the molybdenum oxide or cobalt molybdate (spectrum not reported). This result is in agreement with the absence of any precipitate after the maturation as the Co loading induced by the atomic ratio $\mathrm{Co} / \mathrm{Mo}$ of this salt is low and as there is no ammonium counterions.

The Cobalt being introduced as counterion of the HPA, the Co/Mo ratio is defined by the stoechiometry of the salt but it is lower than the optimum one (about 0.5) defined experimentally for conventional preparations [34]. This ratio can be increased by using cobalt salts of the reduced Keggin HPA $\left(\mathrm{Co}_{7 / 2} \mathrm{PMo}_{12} \mathrm{O}_{40}\right)$, the preparation of which was described elsewhere [21]. Oxidic precursors were prepared with impregnating solutions containing this 
reduced entity and it has been shown by a polarographic analysis of the washing solution of the solid that the HPA is preserved upon impregnation on alumina and drying under $\mathrm{N}_{2}$ [35]. Nevertheless, after calcination under $\mathrm{N}_{2}$ at $400^{\circ} \mathrm{C}$ followed by transfer in the wet air, the reduced HPA is decomposed into reduced polymolybdate species as well as into $\mathrm{AlMo}_{6}$ entities. But after calcination under air, followed by transfer in wet atmosphere, only $\mathrm{AlMo}_{6}$ entities are evidenced by both the Raman spectra of the corresponding solids and the polarographic analysis of their washing solutions (not shown here) [35].

An increase of the Co/Mo atomic ratio can also be obtained with the use of a substituted Keggin HPA. Indeed, it is possible to prepare the $\mathrm{PCoMo}_{11} \mathrm{O}_{40} \mathrm{H}\left(\mathrm{NH}_{4}\right)_{6}$ ammonium salt [36] in which the Co is in a substitution position of a Mo atom of the Keggin sphere. Then, by exchange of the ammonium ions by cobalt atoms, we directly obtain a solution containing the entities to be deposited $\left(3 \mathrm{Co}^{2+}, \mathrm{PCoMo}_{11} \mathrm{O}_{40} \mathrm{H}^{6-}\right)$. Indeed the Raman spectrum of this solution, reported in figure $10 \mathrm{c}$, is characteristic of this HPA [33, 37]. This solution allowed us to prepare an oxidic precursor with a $\mathrm{Co} / \mathrm{Mo}$ atomic ratio of 0.36 as compared to 0.29 for $\mathrm{Co}_{7 / 2} \mathrm{PMo}_{12} \mathrm{O}_{40}$. Upon deposition on alumina, the HPA structure is not preserved as shown by Raman spectroscopy (Fig 10d). Its decomposition, induced by the buffer effect of the alumina, induces the formation of $\mathrm{AlMo}_{6}$ entities, which are recovered after calcination and transfer in the wet atmosphere.

Table 3 gives the thiophene conversion of a 14 wt $\% \mathrm{MoO}_{3}$ versus the $\mathrm{Co} / \mathrm{Mo}$ ratio of these HPA-based catalysts. It can be noticed that at low Co content, the activities are similar whatever the starting material used (lines 1, 3 and 5). This means that no improvement of the promoter effect is observed with these HPAs at low content. Nevertheless, the conversion obtained with the Keggin type HPAs shows an improvement at high metal loading as compared to $\mathrm{P}$ based conventional preparations (lines 2, 4, 6 and 7). It could firstly be assigned to an increase of the Co and Mo dispersion thanks to the absence of any precipitation during the maturation, which is at least due to the absence of ammonium counterions. Moreover, the fact that the Keggin based catalysts are more active than the conventional phosphorus based ones can be discussed in terms of a better interaction between Co and Mo entities. Indeed, the conventional imprenating P-based solutions contain the P-Mo and Co entities but they also contain other ions such as $\mathrm{NH}_{4}{ }^{+}$for the AHM based one and free phosphates for the $\mathrm{MoO}_{3}$ based one. One can suppose that these ions, which are not present in the Keggin based solutions, can decrease at high metal loadings the interaction between Co and Mo entities in the impregnating solution. Indeed we have shown in previous works [21, 
22, 35] by ${ }^{31} \mathrm{P}$ NMR spectroscopy that a strong interaction exists in solution between the Keggin HPAs and the $\mathrm{Co}^{2+}$ ions, which is due to the lack of counterions such as ammonium, phosphates or nitrates encountered in the conventional solutions. For the reduced $\mathrm{Co}_{7 / 2} \mathrm{PMo}_{12} \mathrm{O}_{40}$ based catalyst, this interaction is maintained on the dried catalyst thanks to the stability of the four-electrons reduced compound at high $\mathrm{pH}$ value (up to 7-8), near the isoelectric point of the alumina support. This should limit the fraction of cobalt atoms involved in the formation of the well-known surface " $\mathrm{CoAl}_{2} \mathrm{O}_{4}$ " species that is unavailable for the formation of the active CoMoS phase. We also notice that, for the reduced HPA based catalysts, differences are observed between solids calcined in nitrogen and air (lines 6 and 7). Indeed, the conversion of the reduced HPA based catalyst calcined in $\mathrm{N}_{2}$ is slightly higher than the one calcined in air. This should be assigned to the different nature of the supported oxomolybdate phase which is sulfided to give the active phase. Finally, the very high activity obtained by using $\mathrm{Co}_{3} \mathrm{PCoMo}_{11} \mathrm{O}_{40} \mathrm{H}$ as starting material can also be explained by the absence of $\mathrm{NH}_{4}{ }^{+}$counterions and by a better interaction between Co and Mo atoms, since one Co atom is included in the Keggin sphere (line 8). Although this entity is decomposed upon impregnation and drying, we suppose that the proximity between Co and Mo in the impregnating solution is maintained after impregnation, thus inhibiting the migration of Co inside the alumina lattice.

It can be noticed that similar results were obtained with silicomolybdate Keggin based HPAs [38].

\section{New CoMo impregnating solutions}

It thus appeared that the use of HPA as starting material is an interesting way to prepare very efficient catalysts. For the preparation of the impregnating solution, we therefore propose the use of Anderson CoMo based HPA. In these Anderson based structure it can be considered that the Co atoms are chelated directly by the Mo atoms. Two types of heteropolyanions exist i.e. the 6 molybdocobaltate anion, an analog of the $\mathrm{AlMo}_{6}$ and the decamolybdocobaltate $\left(\mathrm{Co}_{2} \mathrm{Mo}_{10} \mathrm{O}_{38} \mathrm{H}_{4}{ }^{6-}\right)$ [39] (Fig 2e), which can be considered as the dimer of the former one. In both entities the $\mathrm{Co}^{3+}$ atoms are surrounded by a crown of molybdenum octahedra. In order to have a high $\mathrm{Co} / \mathrm{Mo}$ atomic ratio, cobalt salts of these HPAs [40, 41] have been prepared, which moreover allows us to avoid the presence of any foreign counterions such as ammonium or nitrate.

In this paper we will only consider the decamolybdocobaltate cobalt salt $\left(\mathrm{Co}_{3} \mathrm{Co}_{2} \mathrm{Mo}_{10} \mathrm{O}_{38} \mathrm{H}_{4}\right)$ as it permits to prepare oxidic precursors with a Co/Mo ratio 
corresponding to the optimum one for a classical preparation $(\mathrm{Co} / \mathrm{Mo}=0.5)$. Simulations of the experimental EXAFS signal of the oxidic dried (Fig 11) performed with the bulk starting material $\mathrm{Co}_{3} \mathrm{Co}_{2} \mathrm{Mo}_{10} \mathrm{O}_{38} \mathrm{H}_{4}$ crystallographic data gave very satisfactory results, clearly confirming the preservation of these compounds until the drying step of the preparation [13]. Results of the simulation, given in table 4, show a good agreement with the structural data of the starting salt $\mathrm{Co}_{3} \mathrm{Co}_{2} \mathrm{Mo}_{10} \mathrm{O}_{38} \mathrm{H}_{4}$ [41]. This preservation, that is in agreement with the $\mathrm{pH}$ stability domain of this HPA in aqueous solution, is also confirmed by XANES spectroscopy. Indeed the CoK edge XANES spectrum of the dried oxidic precursor, that is reported in figure 12, exhibits a broad line with two components at 7733 and $7725 \mathrm{eV}$ that correspond respectively to the $\mathrm{Co}^{3+}$ central heteroatom and to the $\mathrm{Co}^{2+}$ atoms in counterions position. Raman spectroscopy also evidenced this preservation whereas after calcination and transfer in the wet air, the Raman spectra only exhibited the features of the well dispersed $\mathrm{AlMo}_{6}$ entities (spectra not reported).

Figure 13 shows the thiophene conversion versus the Mo loadings of these $\mathrm{Co}_{3} \mathrm{Co}_{2} \mathrm{Mo}_{10} \mathrm{O}_{38} \mathrm{H}_{4}$ based catalysts. The catalytic performances of reference catalysts with the same metal loadings are also reported. The classical volcano curve is observed for the classical preparation. Whatever the Mo loading, the HPA based catalysts are more efficient than the reference ones. At high Mo loading this improvement is assigned to the better dispersion of the active phase as the oxidic precursor is homogeneous and no bulk oxide $\left(\mathrm{CoMoO}_{4}\right.$ or $\left.\mathrm{MoO}_{3}\right)$ is evidenced by Raman spectroscopy. The improvement at high Mo loading is therefore assigned to the improvement of the dispersion as the entity is preserved upon deposition, which permits to avoid any precipitation.

Better performances are also observed at low Mo loading (Fig 13). This could only be assigned to a better promoting effect as the morphology (length and stacking) of the CoMoS is similar to the reference one [13]. Thus, this suggests that the preservation of the starting HPA during the maturation step enables us to avoid the loss of Co atoms inside the alumina support. These later ones are thus available for the decoration of the molybdenum disulfide crystallites.

\section{Impregnating solutions with chelating agents}

An improvement of the promoting effect has thus been obtained with the decamolybdocobaltate HPA, a structure in which the Co heteroatom can be considered as chelated by the Mo ones. But it is now well admitted that the introduction of a complexing agent (citric acid, NTA....) had a beneficial effect on the catalytic performances [42-44]. 
Typical example of such study concerns the introduction of Ethylenediamine (En) in a conventional CoMo impregnating solution [45]. A complete spectroscopic study (Raman, UV-Visible...) has shown that the main species present in the impregnating solutions are the well known $\mathrm{MoO}_{4}{ }^{2-}$ monomer (the $\mathrm{pH}$ being 9 after addition of the complexing agent) and a $\mathrm{Co}(\mathrm{En}) 3^{3+}$ complex. CoMo based catalysts were prepared by incipient wetness impregnation of an alumina support with developed textural features (Pore volume $=1 \mathrm{~cm}^{3} / \mathrm{g}, \mathrm{SSA}=350$ $\mathrm{m}^{2} / \mathrm{g}$ ). UV-Visible and Raman spectroscopy showed that these species are preserved at the maturation step [45-47]. Upon drying, the molybdenum concentration inside the porosity increases, thus inducing the formation of polymolybdate entities, characterized by a Raman line at $950 \mathrm{~cm}^{-1}$, while the Co-En complex is preserved due to its high temperature stability and probable interaction with the alumina surface (spectra not reported here). After calcination and transfer in the wet air, the Raman spectrum exhibits the main features characteristic of the well dispersed $\mathrm{AlMo}_{6}$ entities whereas $\mathrm{Co}^{2+}$ atoms inside the alumina lattice are evidenced by UV-Visible spectroscopy (The reduction of $\mathrm{Co}^{3+}$ to $^{2+2+}$ is due to the decomposition products of En during calcination). We clearly showed that En allowed us to increase the metal loading (up to 5.2 atoms per $\mathrm{nm}^{2}$ i.e. $30 \mathrm{wt} \% \mathrm{MoO}_{3}$ with the support used in this study) with preservation of the dispersion [45]. An increase of the thiophene conversion is observed at very high loading as compared to conventional CoMo catalysts (Table 5). This can be explained by the absence of bulk oxides such as $\mathrm{MoO}_{3}$ or $\mathrm{CoMoO}_{4}$ [46] generally observed at these high Mo loadings. Recently, J. A. Beerwerff [26] et al showed that the use of complexing agents, such as citric acid, induces a better dispersion of molybdenum entities inside the alumina extrudates by decreasing the interaction between Mo and alumina. Indeed, this inhibits the formation of $\mathrm{AlMo}_{6}$ entities in large amount near the outer surface of these extrudates that could be obtained after impregnation with an $\mathrm{AHM}$ solution on $\mathrm{Al}_{2} \mathrm{O}_{3}$.

A higher conversion is also observed at lower Mo and Co loadings ( 3 Mo atoms per $\mathrm{nm}^{2}$ i.e. $14 \mathrm{wt} \% \mathrm{MoO}_{3}$ with the support used in this study), when En is introduced in the impregnating solution (Table 5: lines 1 and 2). This should be assigned to the better promoting effect of the cobalt as the preservation of the Co entities during maturation permits to avoid the loss of Co atom inside the alumina support or in the aforementioned CoMo oxyhydroxyde phase. It should also be noticed that upon increasing the Mo loading, the promoting factor (conversion ratio between promoted and unpromoted catalysts at the same Mo loading) remains constant for a simultaneous impregnation with En (about 6) [47].

More recently, others authors have proposed the use of complexing agents (En, EDTA or NTA...) $[43,48]$ for the preparation of oxidic precursors and have showed that an 
improvement of the performances can also be obtained without any calcination before the activation. But in that case, the effect is quite different as this improvement has to be assigned to the modification of the genesis of the active CoMoS phase $[43,48,49]$.

Thus, whatever the nature of the complexing agent, it can be considered that their use is motivated by the need to prepare impregnating solutions in which the Mo and/or Co chelated entities are preserved during the maturation step, which permit to improve the dispersion as well as the promoting effect of the Cobalt.

\section{Conclusion}

The aim of this paper is to be more comprehensive than exhaustive through a dedicated choice of results we obtained and that we completed with some litteratur data. A molecular approach based on well defined examples has allowed us to discuss the chemistry that occurs during the maturation, based on the hypothesis that no limitation is induced by the porosity. It has been shown that the alumina support is not inert and the concept of dissolution/dispersion and dissolution/precipitation has permitted to clearly define the nature of the deposited phase during the preparation of the oxidic precursor. It has thus been deduced that the nature of the deposited entities depends only on the chemistry of the solution in the pores of the alumina support, taking into account all the different species that can be formed inside it. However after drying and calcination this is always the same dispersed polymolybdate phase that is obtained which shows the levelling effect of this thermal treatment.

However, at high Mo loading, an improvement of the dispersion of the oxomolybdate phase can be obtained using more stable starting anion than the aforementioned $\mathrm{AlMo}_{6}$ or CoMo oxyhydroxide one. This can be obtained by adding phosphorus in the impregnating solution that permits to avoid any precipitation during the maturation, which is at the origin of the limit of good dispersion. Similar effect can be obtained with the use of phosphomolybdic cobalt salt, which permits moreover to avoid the presence of ammonium cations and therefore to avoid any precipitation, which occurs when ammonium is present in the impregnating solution. By using reduced or Co substituted phosphorus based heteropolyanions for the preparation of the impregnating solution it is possible to increase the $\mathrm{Co} / \mathrm{Mo}$ ratio, that is defined by the stoechiometry of the starting molecular precursor. However this ratio remains below the optimum one $(\mathrm{Co} / \mathrm{Mo}=0.5)$ defined for the classical preparation. But impregnating solutions having the optimum $\mathrm{Co} / \mathrm{Mo}$ ratio can be obtained directly by attack of the molybdenum oxide and adding after the cobalt precursor (nitrate, carbonate, ....). 
A better promoting effect of the Co or Ni can also be obtained through the control of the nature of the cobalt species during this maturation step. It was previously performed with the introduction of complexing agents, which enables to limit the loss of Co atom inside the alumina support. A simultaneous monitoring of the Mo and Co deposition can also be achieved with the direct deposition of cobaltomolybdate entities. The preservation upon deposition on the alumina support of the decamolybdocobaltate cobalt salt enables an increase of the dispersion at high Mo loading but also an increase of the promoting effect. Moreover such preparation does not require any calcination, which appearred as a levelling step of the various preparations. Thus in the preparation of HDS oxidic precursor by incipient wetness impregnation, the main determining step is the maturation one since it permits, not only the precursors to diffuse inside the pores of the support, but also the various chemical equilibria to take place. Nevertheless the problem is quite different in the equilibrium adsorption method, in which the concentration of the various species is by far lower. This implies that the chemical equilibria in the solution between the various entities should be different. In that case, the impregnation could be considered as the levelling step of the preparation if different starting materials are used.

Acknowlegments: The authors would like to thank the French industrial companies Elf-Antar, IFP and TOTAL that provided financial support in the frame of the preparation of $\mathrm{PhD}$ thesis. 


\section{References}

[1] H. Tøpsøe, B.S. Clausen, F.E. Massoth, Hydrotreating Catalysis, Springer, Berlin, 1996

[2] X. Carrier, J.F. Lambert and M. Che, J. Am. Chem. Soc. 119 (1997) 10137

[3] L. le Bihan, P.Blanchard, M. Fournier, J. Grimblot, E. Payen, J. Chem. Soc. Faraday Trans. 94 (1998) 937

[4] S. Kasztelan, J. Grimblot, J.P. Bonnelle, E. Payen, H. Toulhoat, Y. Jacquin, Appl. Catal. 7 (1983) 91

[5] E. Payen, J. Grimblot, S. Kasztelan, J. phys. Chem. 91 (27) (1987) 6642

[6] P. Dufresne, E. Payen, J. Grimblot, J.P. Bonnelle, J. Phys. Chem. 85 (1981) 2344

[7] J.A.R. van Veen, P.A.J.M. Hendriks, R.R. Andrea, E.J.G.M. Romers, A.E. Wilson, J. Phys. Chem. 94 (1990) 5282

[8] N. Spanos, A. Lycourghiotis, J. Catal. 147 (1994) 57

[9] X. Carrier, Thesis, Paris VI University, Paris, France, 1998

[10] G. Plazenet, E. Payen, J. Lynch and B. Rebours, J. Phys. Chem. B 106 (2002) 7013

[11] E.Payen, G. Plazenet, C.Martin, C. Lamonier, J. Lynch, V. Harlé, Stud. Surf. Sci. Catal. $143(2002) 141$

[12] E. Payen, J. Grimblot, J.C. Lavalley, M. Datury, F. Maugé, in Handbook of vibrational spectroscopy, vol 4, p 3004, J.M. Chalmers and P.R. Griffiths Editor, John Wiley \& Sons LTD, 2002

[13] C. Lamonier, C. Martin, J. Mazurelle, V. Harlé, D. Guillaume and E. Payen, Appl. Catal. B, 2006, in press

[14] E. Payen, M.C. Dhamelincourt, P. Dhamelincourt, J. Grimblot, J.P. Bonnelle, Appl. Spectr. 36 (1) (1982) 30

[15] S.M.A.M. Bouwens, J.P.R. Vissers, V.H.J.S. de Beer, R. Prins, J. Catal. 112 (1998) 401

[16] P. Atanasova, T. halachev, J. Uchytil, M. Kraus, appl. Catal. 38 (1988) 235

[17] A. Morales, M.M. Ramirez, Appl. Catal. 23 (1986) 23

[18] Y. Okamoto, T. Gomi, Y. Mori, T. Imanaka, S. Teranishi, react. Kinet. Catal. Lett. 22 (1983) 417

[19] Z. Wang, W. Lu, E. Min, China-Japan-USA symp. Heterog. Catal., Dalian, China 1982, Preprint A25C

[20] M. Jian, R. Prins, Bull. Soc. Chim. Belg. 104 (4/5) (1995) 231

[21] A. Griboval, P. Blanchard, E. Payen, M. Fournier, J.L. Dubois, Stud. Surf. Sci. Catal. 106 (1997) 181 
[22] A. Griboval, P. Blanchard, E. Payen, M. Fournier, J.L. Dubois, Catal. Today, 45 (1998) 277

[23] L. Lyhamn, L. Pettersson, Chem. Script. 12 (1977) 142

[24] H. Kraus, R. Prins, J. Catal. 164 (1996) 251

[25] W.C. Cheng, N.P. Luthra, J. Catal. 109 (1988) 163

[26] J.A. Bergwerff, T. Wisser, B.R.G. Leliveld, B.D. Rossenaar, K.P. de Jong, B.M. Weckhuysen, J. Am. Chem. Soc. 126 (2004) 14548

[27] J.J. Heinerman, A.J. van-Hengstum, M. de-Wind, EP Patent 0469675 A1, 1992

[28] L. Pettersson, I. Anderson, L.O. Öhman, Inorg. Chem., 25 (1986) 4726

[29] D. Zugazagoitia-Herranz, Thesis, Paris VI university, France, 1981

[30] M.T. Pope, in "Heteropoly and Isopoly Oxometalates”, Springer Verlag, Berlin, 1983, and references therein

[31] C. Rocchiccioli-Deltcheff, M. Fournier, R. Franck, R. Thouvenot, Inorg. Chem. 22(2) (1983) 207

[32] R. Thouvenot, M. Fournier, R. Franck, C. Rocchiccioli-Deltcheff, Inorg. Chem. 23 (1984) 598

[33] C. Rocchiccioli-Deltcheff, R. Thouvenot, R. Franck, Spectrochimica Acta. 32A (1976) 587

[34] H. Tøpsøe, B.S. Clausen, F.E. Massoth, Hydrotreating Catalysis, Springer, Berlin, 1996

[35] A. Griboval, P. Blanchard, L. Gengembre, E. Payen, M. Fournier, J.L. Dubois, J.R. Bernard, J. Catal. 188 (1999) 102

[36] A. Griboval, P. Blanchard, E. Payen, M. Fournier, J.L. Dubois, J.R. Bernard, Phosphorus Research Bulletin, 10, 1999, 436

[37] C. Rocchiccioli-Deltcheff, R. Thouvenot, J. Chem. Research (S) (1977) 46, miniprint (1976) 549

[38] A. Griboval, P. Blanchard, E. Payen, M. Fournier, J.L. Dubois, J.R. Bernard, Appl. Catal. A: gen 217 (2001) 173

[39] G. Tsigdinos, Ph.D. Thesis, Boston University graduate school, USA, 1961

[40] C. Martin, C. Lamonier, M. Fournier, O. Mentré, V. Harlé, D. Guillaume and E. Payen, Inorg. Chem. 43 (2004) 4636

[41] C. Martin, C. Lamonier, M. Fournier, O. Mentré, V. Harlé, D. Guillaume, and E. Payen, Chem. Mat. 17 (2005) 4438

[42] J.A.R. van Veen, E. Gerkema, A.M. van der Kraan, A. Knoester, J. Chem. Soc., Chem. Commun. (1987) 1684 
[43] M. Sun, D. Nicosa, R. Prins, Catal. Today, 86 (2003) 173 and references therein

[44] T. Shimizu, K. Hiroshima, T. Honma, T. Mochizuki, M. Yamada, Catal. Today 45 (1998) 271 and references therein

[45] P. Blanchard, Thesis, Lille University, France, 1995

[46] P. Blanchard, E. Payen, J. Grimblot, O. Poulet, R. Loutaty, Stud. Surf. Sci. Catal. 106 (1997) 211

[47] P. Blanchard, C. Mauchaussée, E. Payen, J. Grimblot, O. Poulet, N. Boisdron, R. Loutaty, Stud. Surf. Sci. Catal. 91 (1995) 1037

[48] N. Frizi, Thesis, Lille University, France, 2004

[49] N. Frizi, P. Blanchard, E. Payen, P. Baranek, Chem. Lett. submitted 


\begin{tabular}{|c|c|c|c|c|}
\hline Denomination & Starting materials & $\begin{array}{l}\text { wt \% } \\
\mathrm{MoO}_{3}\end{array}$ & $\mathrm{Co} / \mathrm{Mo}$ & $\begin{array}{c}\mathrm{P} / \mathrm{Mo} \\
\text { or } \\
\mathrm{En} / \mathrm{Co}\end{array}$ \\
\hline $\mathrm{Mo}_{15}(\mathrm{AHM})$ & AHM & 15 & 0 & 0 \\
\hline $\mathrm{Mo}_{20}(\mathrm{AHM})$ & AHM & 20 & 0 & 0 \\
\hline $0.125 \mathrm{CoMo}_{14}(\mathrm{AHM})$ & AHM & 14 & 0.125 & 0 \\
\hline $0.29 \mathrm{CoMo}_{14}(\mathrm{AHM})$ & AHM & 14 & 0.29 & 0 \\
\hline $0.5 \mathrm{CoMo}_{8}(\mathrm{AHM})$ & AHM & 8 & 0.5 & 0 \\
\hline $0.5 \mathrm{CoMo}_{10}(\mathrm{AHM})$ & AHM & 10 & 0.5 & 0 \\
\hline $0.5 \mathrm{CoMo}_{13}(\mathrm{AHM})$ & AHM & 13 & 0.5 & 0 \\
\hline $0.5 \mathrm{CoMo}_{14}(\mathrm{AHM})$ & AHM & 14 & 0.5 & 0 \\
\hline $0.5 \mathrm{CoMo}_{16}(\mathrm{AHM})$ & AHM & 16 & 0.5 & 0 \\
\hline $0.125 \mathrm{CoMo}_{14} \mathrm{P}\left(\mathrm{AHM}, \mathrm{H}_{3} \mathrm{PO}_{4}\right)$ & $\mathrm{AHM}, \mathrm{H}_{3} \mathrm{PO}_{4}$ & 14 & 0.125 & 0.4 \\
\hline $0.29 \mathrm{CoMo}_{14} \mathrm{P}\left(\mathrm{AHM}, \mathrm{H}_{3} \mathrm{PO}_{4}\right)$ & $\mathrm{AHM}, \mathrm{H}_{3} \mathrm{PO}_{4}$ & 14 & 0.29 & 0.4 \\
\hline $0.125 \mathrm{CoMo}_{14} \mathrm{P}\left(\mathrm{MoO}_{3}, \mathrm{H}_{3} \mathrm{PO}_{4}\right)$ & $\mathrm{MoO}_{3}, \mathrm{H}_{3} \mathrm{PO}_{4}, \mathrm{CoCO}_{3}$ & 14 & 0.125 & 0.4 \\
\hline $0.29 \mathrm{CoMo}_{14} \mathrm{P}\left(\mathrm{MoO}_{3}, \mathrm{H}_{3} \mathrm{PO}_{4}\right)$ & $\mathrm{MoO}_{3}, \mathrm{H}_{3} \mathrm{PO}_{4}, \mathrm{CoCO}_{3}$ & 14 & 0.29 & 0.4 \\
\hline $0.125 \mathrm{CoMo}_{14} \mathrm{P}\left(\mathrm{Co}_{3 / 2} \mathrm{PMo}_{12} \mathrm{O}_{40}\right)$ & $\mathrm{Co}_{3 / 2} \mathrm{PMo}_{12} \mathrm{O}_{40}$ & 14 & 0.125 & 0.08 \\
\hline $0.29 \mathrm{CoMo}_{14} \mathrm{P}\left(\mathrm{Co}_{7 / 2} \mathrm{PMo}_{12} \mathrm{O}_{40}\right)$ & $\mathrm{Co}_{7 / 2} \mathrm{PMo}_{12} \mathrm{O}_{40}$ & 14 & 0.29 & 0.08 \\
\hline $0.36 \mathrm{CoMo}_{14} \mathrm{P}\left(\mathrm{Co}_{3} \mathrm{PCoMo}_{11} \mathrm{O}_{40} \mathrm{H}\right)$ & $\mathrm{Co}_{3} \mathrm{PCoMo}_{11} \mathrm{O}_{40} \mathrm{H}$ & 14 & 0.36 & 0.09 \\
\hline $0.5 \mathrm{CoMo}_{6}\left(\mathrm{Co}_{3} \mathrm{Co}_{2} \mathrm{Mo}_{10} \mathrm{O}_{38} \mathrm{H}_{4}\right)$ & $\mathrm{Co}_{3} \mathrm{Co}_{2} \mathrm{Mo}_{10} \mathrm{O}_{38} \mathrm{H}_{4}$ & 6 & 0.5 & 0 \\
\hline $0.5 \mathrm{CoMo}_{9}\left(\mathrm{Co}_{3} \mathrm{Co}_{2} \mathrm{Mo}_{10} \mathrm{O}_{38} \mathrm{H}_{4}\right)$ & $\mathrm{Co}_{3} \mathrm{Co}_{2} \mathrm{Mo}_{10} \mathrm{O}_{38} \mathrm{H}_{4}$ & 9 & 0.5 & 0 \\
\hline $0.5 \mathrm{CoMo}_{11}\left(\mathrm{Co}_{3} \mathrm{Co}_{2} \mathrm{Mo}_{10} \mathrm{O}_{38} \mathrm{H}_{4}\right)$ & $\mathrm{Co}_{3} \mathrm{Co}_{2} \mathrm{Mo}_{10} \mathrm{O}_{38} \mathrm{H}_{4}$ & 11 & 0.5 & 0 \\
\hline $0.5 \mathrm{CoMo}_{13}\left(\mathrm{Co}_{3} \mathrm{Co}_{2} \mathrm{Mo}_{10} \mathrm{O}_{38} \mathrm{H}_{4}\right)$ & $\mathrm{Co}_{3} \mathrm{Co}_{2} \mathrm{Mo}_{10} \mathrm{O}_{38} \mathrm{H}_{4}$ & 13 & 0.5 & 0 \\
\hline $0.5 \mathrm{CoMo}_{16}\left(\mathrm{Co}_{3} \mathrm{Co}_{2} \mathrm{Mo}_{10} \mathrm{O}_{38} \mathrm{H}_{4}\right)$ & $\mathrm{Co}_{3} \mathrm{Co}_{2} \mathrm{Mo}_{10} \mathrm{O}_{38} \mathrm{H}_{4}$ & 16 & 0.5 & 0 \\
\hline $0.28 \mathrm{CoMo}_{14}(\mathrm{AHM})$ & AHM, En & 14 & 0.28 & 6 \\
\hline $0.28 \mathrm{CoMo}_{14} \mathrm{En}(\mathrm{AHM})$ & AHM, En & 14 & 0.28 & 6 \\
\hline $0.28 \mathrm{CoMo}_{20} \mathrm{En}(\mathrm{AHM})$ & AHM, En & 20 & 0.28 & 6 \\
\hline $0.28 \mathrm{CoMo}_{30} \mathrm{En}(\mathrm{AHM})$ & AHM, En & 30 & 0.28 & 6 \\
\hline
\end{tabular}

Table 1: Characteristics of the catalysts: denomination of the catalysts, starting materials used for the preparation of the impregnating solutions, Mo weight loadings expressed as a weight percent of $\mathrm{MoO}_{3}, \mathrm{Co} / \mathrm{Mo}$ atomic ratio and $\mathrm{P} / \mathrm{Mo}$ atomic ratio for the phosphorus based catalysts or En/Co molar ratio for the catalysts prepared with this complexing agent. Otherwise specified, the cobalt salt used for the preparation of the CoMo based solutions is always cobalt nitrate. 


\begin{tabular}{|c|c|}
\hline Catalysts & $\begin{array}{c}\text { Thiophene HDS activity } \\
(\% \text { conversion })\end{array}$ \\
\hline $0.125 \mathrm{CoMo}_{14}(\mathrm{AHM})$ & 14 \\
\hline $0.29 \mathrm{CoMo}_{14}(\mathrm{AHM})$ & 19 \\
\hline $0.125 \mathrm{CoMo}_{14} \mathrm{P}\left(\mathrm{AHM}, \mathrm{H}_{3} \mathrm{PO}_{4}\right)$ & 26 \\
\hline $0.29 \mathrm{CoMo}_{14} \mathrm{P}\left(\mathrm{AHM}, \mathrm{H}_{3} \mathrm{PO}_{4}\right)$ & 14 \\
\hline $0.125 \mathrm{CoMo}_{14} \mathrm{P}\left(\mathrm{MoO}_{3}, \mathrm{H}_{3} \mathrm{PO}_{4}\right)$ & 27 \\
\hline $0.29 \mathrm{CoMo}_{14} \mathrm{P}\left(\mathrm{MoO}_{3}, \mathrm{H}_{3} \mathrm{PO}_{4}\right)$ & \\
\hline
\end{tabular}

Table 2: Catalytic activities of CoMo and CoMoP HDS catalysts 


\begin{tabular}{|c|c|}
\hline Catalysts & $\begin{array}{c}\text { Thiophene HDS activity } \\
(\% \text { conversion })\end{array}$ \\
\hline $0.125 \mathrm{CoMo}_{14} \mathrm{P}\left(\mathrm{AHM}, \mathrm{H}_{3} \mathrm{PO}_{4}\right)$ & 14 \\
\hline $0.29 \mathrm{CoMo}_{14} \mathrm{P}\left(\mathrm{AHM}, \mathrm{H}_{3} \mathrm{PO}_{4}\right)$ & 26 \\
\hline $0.125 \mathrm{CoMo}_{14} \mathrm{P}\left(\mathrm{MoO}_{3}, \mathrm{H}_{3} \mathrm{PO}_{4}\right)$ & 27 \\
\hline $0.29 \mathrm{CoMo}_{14} \mathrm{P}\left(\mathrm{MoO}_{3}, \mathrm{H}_{3} \mathrm{PO}_{4}\right)$ & 15 \\
\hline $0.125 \mathrm{CoMo}_{14} \mathrm{P}\left(\mathrm{Co}_{3 / 2} \mathrm{PMo}_{12} \mathrm{O}_{40}\right)$ & 32 \\
\hline $0.29 \mathrm{CoMo}_{14} \mathrm{P}\left(\mathrm{Co}_{7 / 2} \mathrm{PMo}_{12} \mathrm{O}_{40}\right)$ calc $\mathrm{N}_{2}$ & 30 \\
\hline $0.29 \mathrm{CoMo}_{14} \mathrm{P}\left(\mathrm{Co}_{7 / 2} \mathrm{PMo}_{12} \mathrm{O}_{40}\right)$ calc air & 39 \\
\hline $0.36 \mathrm{CoMo}_{14} \mathrm{P}\left(\mathrm{Co}_{3} \mathrm{PCoMo}_{11} \mathrm{O}_{40} \mathrm{H}\right)$ & $\mathrm{CoM}$ \\
\hline
\end{tabular}

Table 3: Catalytic activities in HDS of thiophene of conventional CoMoP and Keggin based CoMoP HDS catalysts 


\begin{tabular}{|c|c|c|c|c|c|}
\hline & Co- O (1) & Co- O (2) & Co- Co & Co- Mo (1) & Co - Mo (2) \\
\hline $\mathbf{N}$ & 5.18 & 1.50 & 0.61 & 0.52 & 2.46 \\
$\mathbf{R}(\AA)$ & 1.90 & 2.10 & 2.82 & 2.97 & 3.29 \\
$\Delta \boldsymbol{\sigma}(\AA)$ & 0.08 & 0.07 & 0.09 & 0.10 & 0.10 \\
\hline$\Delta \mathbf{E}(\mathbf{e V})$ & -1.86 & & \\
résidue & 0.023 &
\end{tabular}

Table 4 : refinement of the EXAFS signals of the $\mathrm{Co}_{3} \mathrm{Co}_{2} \mathrm{Mo}_{10} \mathrm{O}_{38} \mathrm{H}_{4}$ based oxidic precursor at the Co K edge 


\begin{tabular}{|c|c|}
\hline Catalysts & $\begin{array}{c}\text { Thiophene HDS activity } \\
(\% \text { conversion })\end{array}$ \\
\hline $0.28 \mathrm{CoMo}_{14}(\mathrm{AHM})$ & 25 \\
\hline $0.28 \mathrm{CoMo}_{14} \mathrm{En}(\mathrm{AHM})$ & 33 \\
\hline $0.28 \mathrm{CoMo}_{20} \mathrm{En}(\mathrm{AHM})$ & 38 \\
\hline $0.28 \mathrm{CoMo}_{30} \mathrm{En}(\mathrm{AHM})$ & 42 \\
\hline
\end{tabular}

Table 5: Catalytic activities of CoMo and CoMoEn HDS catalysts 